\title{
Poly(thioether phenyl acrylate) Based Micelles Show Exclusively ROS-triggered Breakdown
}

Irene Piergentili ${ }^{\mathrm{a}}$, Pepijn R. Bouwmans ${ }^{\mathrm{a}}$, Luuk Reinalda ${ }^{\mathrm{a}}$, Reece W. Lewis ${ }^{\mathrm{a}}$, Benjamin Klemm ${ }^{\mathrm{a}}$, Huanhuan Liu ${ }^{b}$, Robin M. de Kruijff ${ }^{b}$, Antonia G. Denkova ${ }^{\mathrm{b}}$, Rienk Eelkema ${ }^{\mathrm{a}, *}$

${ }^{a}$ Delft University of Technology, Department of Chemical Engineering, Van der Maasweg 9, $2629 \mathrm{HZ}$ Delft, The Netherlands

${ }^{\mathrm{b}}$ Delft University of Technology, Department of Radiation Science and Technology, Mekelweg 15, 2629 JB Delft, The Netherlands

* corresponding author: r.eelkema@tudelft.nl

block copolymers, responsive materials, controlled release, reactive oxygen species, logic gates, polymer micelles.

\begin{abstract}
In certain tumor and diseased tissues, reactive oxygen species (ROS), such as $\mathrm{H}_{2} \mathrm{O}_{2}$, are produced in higher concentrations than in healthy cells. To date, only few examples of drug delivery and release systems responds selectively to these small but significantly elevated ROS concentrations. In addition, assuring the stability of the polymer-based carrier in "healthy" biological conditions is still a challenge in the field of oxidation-sensitive materials.

Here, we present ROS-responsive block copolymer micelles capable of achieving micellar disruption over days in the presence of $2 \mathrm{mM} \mathrm{H}_{2} \mathrm{O}_{2}$ and within hours under higher concentrations of $\mathrm{H}_{2} \mathrm{O}_{2}(60-600 \mathrm{mM})$. At the same time, these micelles are stable for over two weeks in oxidantfree physiological $\left(\mathrm{pH}=7.4,37^{\circ} \mathrm{C}\right)$ and for at least six days in mildly acidic $(\mathrm{pH}=5.0$ and $\mathrm{pH}=$ $6.0,37^{\circ} \mathrm{C}$ ) conditions. The observed selectivity is programmed into the material using a 4 (methylthio)phenyl ester based logic gate. Here, oxidation of the thioether moiety results in a large increase in ester hydrolytic lability, effectively switching the ester hydrolysis from off to on. The concept represents a step forward to realize signal responsive drug delivery materials capable of selective action in biological environments.
\end{abstract}




\section{Introduction}

Smart materials that respond to external stimuli have emerged as an efficient platform to obtain targeted nanotherapeutics. Historically, amphiphilic block copolymers that spontaneously selfassemble in an aqueous environment are used as carriers to solubilise important, but poorly water soluble anti-inflammation and anti-cancer drugs in the bloodstream. ${ }^{[1]}$ Still, these systems can suffer from nonspecific biodistribution and uncontrolled drug release, causing ineffective treatment or undesired side effects in the patient. ${ }^{[2]}$ Therefore, the need for personalized therapeutics inspired researchers to study materials responsive to abnormal biological changes specifically caused by the diseased cells. Over the last decades, intelligent polymers have been developed to be responsive to several stimuli, like $\mathrm{pH},{ }^{[3]}$ temperature, ${ }^{[4]}$ and small molecule or biomacromolecular signals. ${ }^{[5]}$

Reactive oxygen species (ROS), such as hydrogen peroxide, regulate fundamental physiological processes in cells, including oxygen metabolism and signaling pathways. ${ }^{[6-7]}$ However, in cancers and inflammatory, ${ }^{[6-8]}$ cardiovascular ${ }^{[9]}$ or neurodegenerative diseases,${ }^{[10-11]}$ ROS are produced at a rate that natural antioxidant mechanisms, like enzymes (e.g. superoxide dismutase, catalase), cannot overcome. ${ }^{[12-14]}$ Elevated intracellular $\mathrm{H}_{2} \mathrm{O}_{2}$ concentrations in diseased tissues are typically between 10 and $100 \mu \mathrm{M},{ }^{[15-16]}$ and can go up to $10 \mathrm{mM} .^{[17]}$ This change in the oxidative state of the cellular environment can be used as a trigger for selective local cargo release. ${ }^{[18-20]}$

The pioneering work of Hubbell et al. in 2004 reported the first oxidation-sensitive polymeric vesicles for drug delivery purposes, degradable in $10 \mathrm{~h}$ in presence of $10 \mathrm{vol} \% \mathrm{H}_{2} \mathrm{O}_{2} \cdot{ }^{[21]}$ Since then, the same group have applied that principle in several organic nanoparticles including micelles and vesicles. ${ }^{[22-24]}$ Their responsiveness is based on the oxidation of hydrophobic thioethers to more hydrophilic sulfoxides and sulfones. Oxidation leads to more water-soluble polymeric materials, and therefore, less stable micelles, allowing for the release of the incorporated cargo. ${ }^{\text {[25] }}$ In most of these examples, exceedingly high concentrations of $\mathrm{H}_{2} \mathrm{O}_{2}(2.0-10 \mathrm{vol} \%)$ are required to disassemble the carrier within hours.

In contrast, boronate-based polymers have been extensively studied in the last 10 years because their sensitivity to $\mathrm{H}_{2} \mathrm{O}_{2}$ is in the sub-millimolar range. ${ }^{[26-27]}$ Implementing boronic esters in a phenol-based polymeric backbone, Almutairi et al. reported in 2012 a cascade degradable nanoparticle sensitive to only $50 \mu \mathrm{M}$ of $\mathrm{H}_{2} \mathrm{O}_{2} \cdot{ }^{[28]}$ This unique example of a nanocarrier sensitive to biologically relevant concentrations of $\mathrm{H}_{2} \mathrm{O}_{2}$ was, however, accompanied by poor control over 
drug release (fast initial burst effect and non-specific release) during degradation of the nanocarrier. Various mechanisms of $\mathrm{H}_{2} \mathrm{O}_{2}$ triggered drug release based on the boronate cleavage methodology have been developed, including the degradation of polymeric backbones, ${ }^{[29]}$ activation of prodrugs ${ }^{[30-31]}$ and destruction of the amphiphilic block copolymer structure, usually by unmasking a more hydrophilic aliphatic acid (e.g. polyacrylic acid) ${ }^{[32-34]}$. In addition, boronic esters are also susceptible to hydrolysis and glycolysis at mildly acidic $\mathrm{pH}$, forming diols and boronic acids. ${ }^{[35]}$ The multi-responsiveness of boronates makes it a versatile moiety for biomedical materials, but can also pose a problem in terms of selectivity, causing off-target release. The need in the field of ROS-responsive materials resides currently in the design of systems with a cascade logic gate behaviour, able to ensure specific and robust control over the performance of drug carriers. ${ }^{[36]}$

In this work, we present an oxidation-sensitive bond cleavage method that merges the responsivity of thioethers toward oxidation, with the tunability of ester hydrolysis through a reactivity switch. In the design of the system, we chose thioanisole type groups as our ROS-responsive moieties. First, we considered that the oxidation potential of aromatic thioethers is in the ideal range to undergo oxidation by $\mathrm{H}_{2} \mathrm{O}_{2} \cdot{ }^{[37]}$ The oxidation of aliphatic thioethers to sulfoxides or sulfones has been extensively applied in polymeric materials to increase the hydrophilicity of the chain. ${ }^{[21,38-41]}$ However, it is known that the oxidation of aromatic thioethers to the corresponding sulfoxide and sulfone is insufficient to achieve a desired solubility switch. ${ }^{[42]}$ Instead, we decided to use sulfide oxidation to increase the hydrolytic lability of a nearby ester, thereby introducing a more effective solubility switch. Knowing that electron withdrawing groups on the aromatic ring of phenyl acetate esters increase the electrophilicity of the ester, ${ }^{[43]}$ our idea was to achieve a reactivity switch when the electron donating thioether is oxidized into a more electron withdrawing group, such as the corresponding sulfoxide or sulfone. Therefore, $\mathrm{H}_{2} \mathrm{O}_{2}$-triggered thioether oxidation would activate the adjacent ester functionality towards hydrolysis.

We synthesized two amphiphilic block copolymers with different lengths of N,Ndimethylacrylamide as a hydrophilic block and 4-(methylthio) phenyl acrylates as a hydrophobic part of the chain. In aqueous environment, these macromolecules self-assemble into micelles with diameters between 30 and $50 \mathrm{~nm}$, which is an appropriate size range for drug nanocarriers. ${ }^{\text {[4] }}$ When $\mathrm{H}_{2} \mathrm{O}_{2}$ is added, the oxidation of sulfide to sulfoxide leads to the removal of 4(methylsulfinyl)phenol 1 and 4-(methylsulfonyl)phenol 2 units through hydrolysis, turning the 
hydrophobic core into a more hydrophilic acrylate anion block and finally obtaining micellar disintegration (Figure 1). These ester-based polymeric micelles show great stability towards hydrolysis at neutral and acidic $\mathrm{pH}$, demonstrating specific responsiveness towards oxidation by cascade logic behaviour.
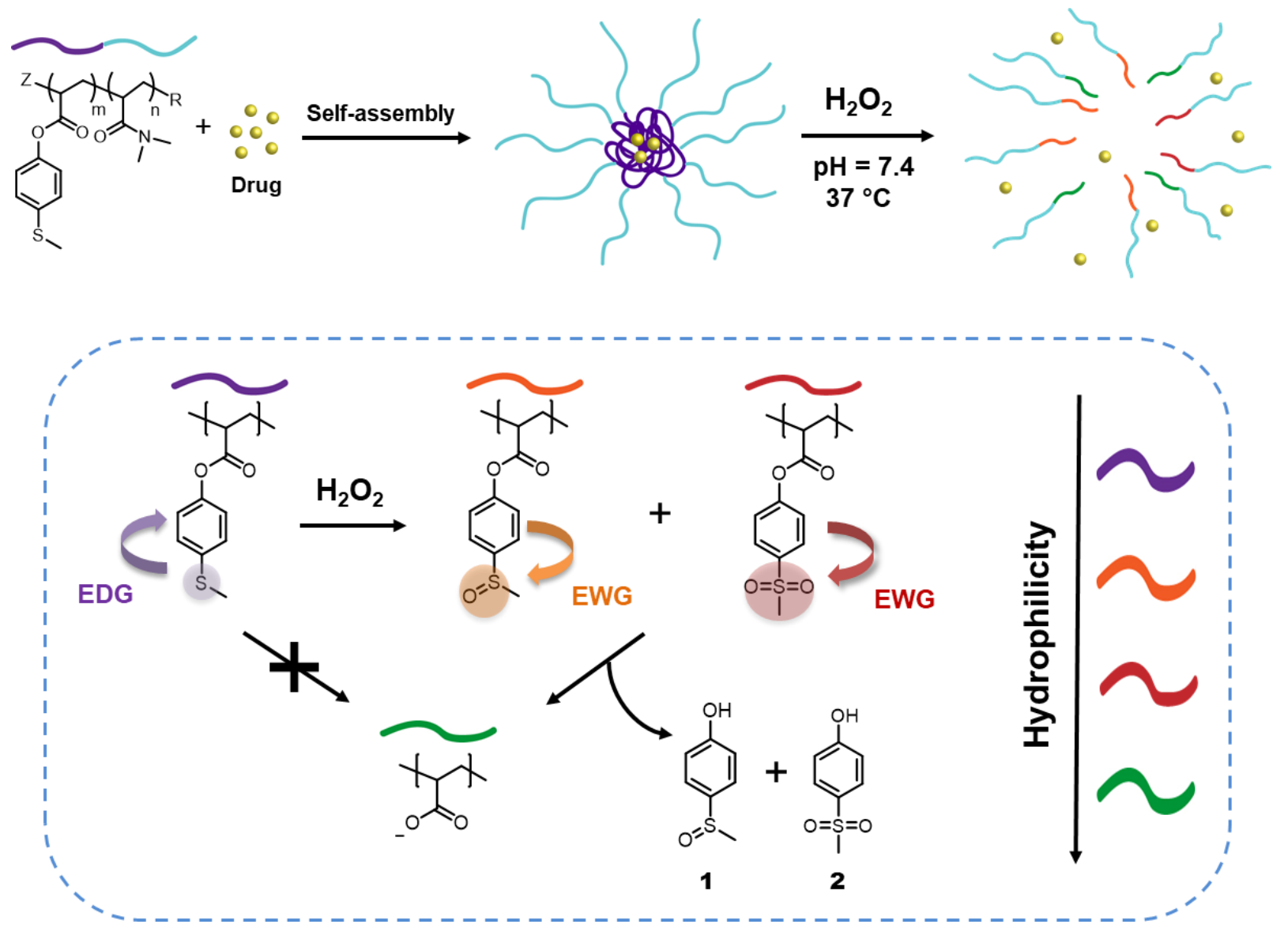

Figure 1. General concept: drug release from ROS-responsive micelles, triggered by the hydrolytic cleavage of ester bonds through switching from an electron donating (EDG) thioether group to electron withdrawing (EWG) sulfoxide and sulfone groups upon oxidation by $\mathrm{H}_{2} \mathrm{O}_{2}$. 


\section{Results and Discussion}

\subsection{Synthesis and characterization of $\mathbf{p}\left(\mathrm{DMA}_{\mathrm{n}}-\mathrm{b}-\mathrm{MTPA}_{\mathrm{m}}\right)$}

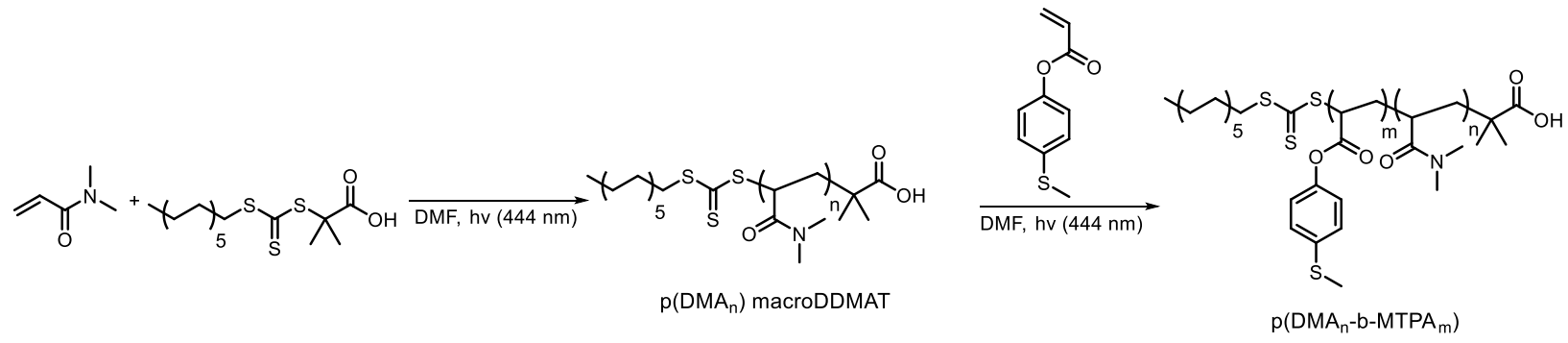

Scheme 1 Synthetic route for preparation of ROS-responsive $p\left(D_{M} A_{n}-b-M T P A_{m}\right)$ diblock copolymers via light initiated RAFT polymerization.

Table 1. Characterization of the block copolymers $p\left(\mathrm{DMA}_{n}-\mathrm{b}-\mathrm{MTPA}_{\mathrm{m}}\right)$.

$\begin{array}{ccccc}\text { Code } & \text { Polymer } & \mathbf{M}_{\mathbf{n}, \text { conv }}(\mathbf{k D a}) & \mathbf{M}_{\mathbf{n}, \mathbf{G P C}}(\mathbf{k D a}) & \boldsymbol{\oplus}\left(\mathbf{M}_{\mathbf{w}} / \mathbf{M}_{\mathbf{n}}\right) \\ \text { DMA130 } & \mathrm{p}\left(\mathrm{DMA}_{130}\right) & 13.2 & 13.0 & 1.13 \\ \text { DMA102 } & \mathrm{p}\left(\mathrm{DMA}_{102}\right) & 10.5 & 11.1 & 1.28 \\ \text { PM16 } & \mathrm{p}\left(\mathrm{DMA}_{130}-\mathrm{b}-\mathrm{MTPA}_{16}\right) & 16.3 & 16.0 & 1.16 \\ \text { PM32 } & \mathrm{p}\left(\mathrm{DMA}_{102}-\mathrm{b}-\mathrm{MTPA}_{32}\right) & 16.7 & 17.4 & 1.27\end{array}$

We synthesized the amphiphilic $\mathrm{p}\left(\mathrm{DMA}_{\mathrm{n}}-\mathrm{b}-\mathrm{MTPA}_{\mathrm{m}}\right)$ block copolymers through sequential lightinitiated RAFT polymerization (Scheme 1). ${ }^{[45]}$ The choice of extending poly(N,Ndimethylacrylamide) macroDDMAT with 4-(methylthio) phenyl acrylate (MTPA) was due to the less successful chain extension when we attempted the opposite order. First, p(DMA) macroDDMAT was prepared using 2-(dodecylthiocarbonothioylthio)-2-methylpropionic acid (DDMAT) as the RAFT agent to obtain 130 and 102 DMA unit long polymeric chains (Table S1, Supporting Information). Then, the chain extension of hydrophilic macromolecular chain transfer agents $\mathrm{p}\left(\mathrm{DMA}_{130}\right)$ macroDDMAT and $\mathrm{p}\left(\mathrm{DMA}_{102}\right)$ macroDDMAT with MTPA (Table S2, Supporting Information) produced PM16 and PM32. ${ }^{1} \mathrm{H}$ NMR spectra of the block copolymers in $\mathrm{CDCl}_{3}$ (Figure S1, Supporting Information) showed characteristic (broadened) signals of both DMA and MTPA, with the ratio of their integrations in line with what was expected from conversion data. In agreement with the ${ }^{1} \mathrm{H}$ NMR results, GPC traces (Figure S2, Supporting Information) confirmed successful chain extension for both polymers through increase in molecular weight of a single peak. Thus, we obtained two block copolymers (Table 1), allowing 
investigation into the influence of varying hydrophobic block/hydrophilic block ratios on micelle formation and drug loading efficiency. ${ }^{[46]}$

\subsection{Preparation and characterization of $\mathbf{p}\left(\mathrm{DMAn}_{\mathrm{n}}-\mathrm{b}-\mathrm{MTPA}\right)$ micelles}

PM16 and PM32 micelles with a p(MTPA) core and a p(DMA) corona were prepared by a solvent evaporation method using THF. Addition of sodium phosphate buffer $(\mathrm{PB}, 100 \mathrm{mM}, \mathrm{pH}=7.4)$ to the solubilized polymers led to micellar dispersions of PM16 and PM32. The average hydrodynamic diameter $\left(\mathrm{D}_{\mathrm{H}}\right)$ of the micelles at $1.0 \mathrm{mg} / \mathrm{mL}$ measured by DLS was $31.6 \pm 0.5$ and $42.4 \pm 0.9 \mathrm{~nm}$ for PM16 and PM32, respectively (Table 2). With PM32 showing a larger $\mathrm{D}_{\mathrm{H}}$, the hydrodynamic size appeared to be correlate with the length of the hydrophobic block. ${ }^{[47]}$ TEM images (Figure $3 \mathrm{C}, \mathrm{D}$ ) acquired from micellar dispersions at $1.0 \mathrm{mg} / \mathrm{mL}$ demonstrated the formation of spherical particles, ascribable to micelles. The particle analysis based on these TEM images gave an average diameter of $17.7 \pm 3.1 \mathrm{~nm}$ for PM16 (Figure S5A, Supporting Information) and $25.8 \pm 3.1 \mathrm{~nm}$ for PM32 (Figure S5B, Supporting Information). Cryo-EM analysis further confirmed the spherical morphology of both PM16 (Figure S6B, Supporting Information) and PM32 (Figure S7C, Supporting Information) micelles, with an average diameter of $10.4 \pm 1.2$ (Figure S6A, Supporting Information) and 19.2 $\pm 2.3 \mathrm{~nm}$ (Figure S7A, Supporting Information), respectively. Combined, these analyses demonstrated that both polymers formed micelles with the appropriate size range for nanotherapeutics, ${ }^{[48]}$ and are thus possibly loadable with hydrophobic cargo. $^{[49]}$

Table 2. Size of PM16 and PM32 micelles measured by DLS, TEM and Cryo-EM.

\begin{tabular}{cccc} 
Polymer & $\begin{array}{c}\mathbf{D}_{H} \\
(\mathbf{n m})\end{array}$ & $\begin{array}{c}\mathbf{D}_{\text {TEM }} \\
(\mathbf{n m})\end{array}$ & $\begin{array}{c}\mathbf{D}_{\text {Cryo-EM }} \\
(\mathbf{n m})\end{array}$ \\
\hline PM16 & $31.6 \pm 0.5$ & $17.7 \pm 3.1$ & $10.4 \pm 1.2$ \\
PM32 & $42.4 \pm 0.9$ & $25.8 \pm 3.1$ & $19.2 \pm 2.3$
\end{tabular}




\section{3. $\mathrm{H}_{2} \mathrm{O}_{2}$ induced oxidation and hydrolysis of $\mathrm{p}\left(\mathrm{DMA}_{\mathrm{n}}-\mathrm{b}-\mathrm{MTPA} \mathrm{A}_{\mathrm{m}}\right)$ micelles}

After characterization of the micelles, we wanted to test their response to $\mathrm{H}_{2} \mathrm{O}_{2}$. The oxidation of organic thioethers with $\mathrm{H}_{2} \mathrm{O}_{2}$ is notably slow and depends on the concentration of both reactants. ${ }^{\text {[4, }}$ ${ }^{50]}$ Thus, we chose to use a large excess of $\mathrm{H}_{2} \mathrm{O}_{2}$ (90 equivalents for PM16 and 46 for PM32) compared to the thioether units of the polymers to obtain an overview of the response times and behavior of these micelles. PM16 (6.7 mM thioether units at $6.8 \mathrm{mg} / \mathrm{mL})$ and PM32 micelles (13 $\mathrm{mM}$ thioether units at $6.8 \mathrm{mg} / \mathrm{mL})$ in $\mathrm{PB} / \mathrm{D}_{2} \mathrm{O} 9: 1$ were combined with $2.0 \mathrm{wt} \% \mathrm{H}_{2} \mathrm{O}_{2}(600 \mathrm{mM})$ at $37{ }^{\circ} \mathrm{C}$ and studied by ${ }^{1} \mathrm{H}$ NMR spectroscopy (Figure 2C and Figure S8 for PM16 and PM32, respectively). The micelles in aqueous media (bottom spectrum, Figure 2C) showed only the $\mathrm{p}\left(\mathrm{DMA}_{\mathrm{n}}\right)$ peaks, caused by the core-corona structure that is typical of polymeric micelles. However, almost immediately after the addition of $\mathrm{H}_{2} \mathrm{O}_{2}$, the ${ }^{1} \mathrm{H}$ NMR spectra revealed the release of $1\left({ }^{1} \mathrm{H}\right.$ NMR spectrum reference in Supporting Information), confirming the oxidation and hydrolysis of the 4-(methylthio)phenyl ester functionalized core of the micelles (Figure 2A).

Figure 2B shows the results of the combined ${ }^{1} \mathrm{H}$ NMR experiments for both polymeric micelles to give a comparative overview of the kinetics for different hydrophobic/hydrophilic block ratios. PM16 micelles exhibited $100 \%$ of degradation of the 4-(methylthio)phenyl ester moieties $3 \mathrm{~h}$ after addition of $\mathrm{H}_{2} \mathrm{O}_{2}$, converting to $87 \%$ of $\mathbf{1}$ and $13 \%$ of $\mathbf{2}$. The PM32 micelles reached the same outcome after $6 \mathrm{~h}$. It is worth noting that the release of these hydrolysis products followed sigmoidal curves. This effect was more significant for the release of $\mathbf{2}$, which showed lag times of $2 \mathrm{~h}$ for PM16 and $4 \mathrm{~h}$ for PM32.

The conversion to $9 \%$ of $\mathbf{1}$ from PM16 and $3 \%$ from PM32 in the first ${ }^{1} \mathrm{H}$ NMR acquisition after the addition of $\mathrm{H}_{2} \mathrm{O}_{2}(\sim 5$ minutes) would suggest that as soon as the oxidation of the sulfide groups occurred, hydrolysis took place as well. This hypothesis is also supported by the absence of broad peaks related to the poly sulfoxide/sulfone in all the spectra acquired. In addition, both polymeric micelles resulted in the same distribution of sulfoxide and sulfone at the end of the degradation, which could be an indication that PM16 and PM32 followed a similar oxidation/hydrolysis mechanism. To asses this hypothesis, it is also interesting to note that PM32 required almost exactly 2 times as long to hydrolyze as PM16, matching the corresponding number of the 4(methylthio)phenyl ester units to oxidize. Moreover, obtaining sigmoidal curves for the formation of degradation products is in line with the fact that both oxidation of thioethers and ester hydrolysis inside polymer micelles in aqueous environment are known to be autocatalytic processes. ${ }^{[23,51]}$ At 
the macromolecular level, when the hydrophobic core becomes more hydrophilic due to sulfur oxidation and ester hydrolysis, the micellar core turns into a more soluble matrix for $\mathrm{H}_{2} \mathrm{O}_{2}$. Thus, the increase of the local concentration of oxidant causes the acceleration of the reaction rate. ${ }^{[23]} \mathrm{A}$ clear indication of this phenomenon was the acceleration that we observed for the approximate complete release of 2 from PM32 in $2 \mathrm{~h}$, after a $4 \mathrm{~h}$ long lag time. In fact, the significantly longer lag time for PM32 than PM16 can easily be explained considering the larger and less accessible hydrophobic core.

A

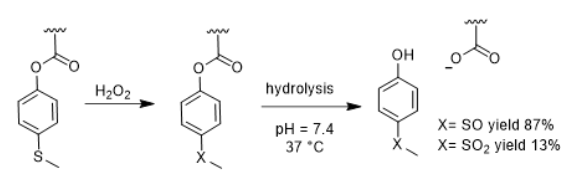

B

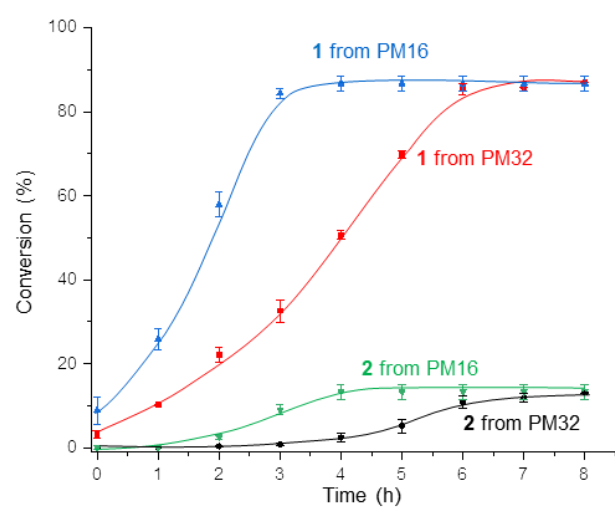

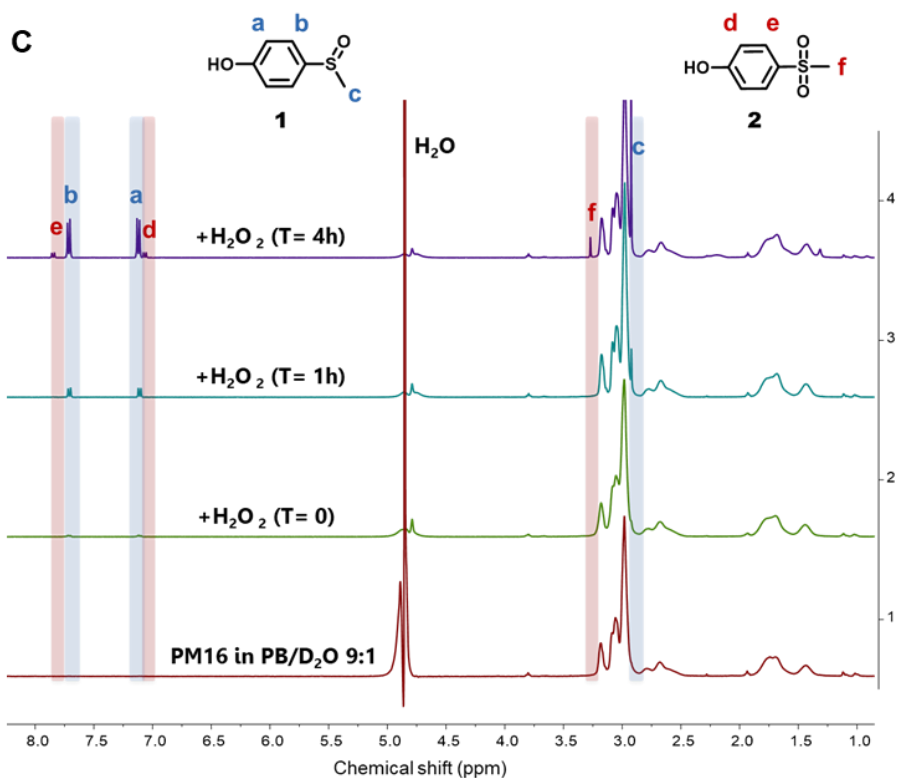

Figure 2. A) Scheme of $\mathrm{H}_{2} \mathrm{O}_{2}$-triggered solubility switch of 4-(methylthio) phenyl acrylate by oxidation induced hydrolysis leading to formation of hydrophilic acrylate anion and removal of $\mathbf{1}$ and 2 from the polymers. B) Conversion measured through ${ }^{1} \mathrm{H}$ NMR spectroscopy of $\mathbf{1}$ and $\mathbf{2}$ upon the addition of $2.0 \mathrm{wt} \%$ of $\mathrm{H}_{2} \mathrm{O}_{2}$ to PM16 and PM32 micellar solutions $(6.8 \mathrm{mg} / \mathrm{mL})$ in PB (100 $\mathrm{mM}, \mathrm{pH}=7.4)$ at $37{ }^{\circ} \mathrm{C}$. The curves are drawn as a guide for the eye. C) ${ }^{1} \mathrm{H}$ NMR of PM16 micelles after treatment with $2.0 \mathrm{wt} \%$ of $\mathrm{H}_{2} \mathrm{O}_{2}$ in $\mathrm{PB}(100 \mathrm{mM}, \mathrm{pH}=7.4) / \mathrm{D}_{2} \mathrm{O} 9: 1$ at $37{ }^{\circ} \mathrm{C}$. 


\subsection{Stability of $p\left(\right.$ DMAn $\left._{n}-b-M T P A_{m}\right)$ micelles}

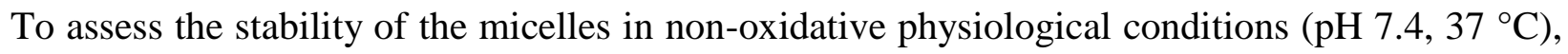
we followed the hydrolysis rate for both PM16 and PM32 micelles by ${ }^{1} \mathrm{H}$ NMR for $144 \mathrm{~h}$ ( 6 days). We did observe the formation of a small amount of 1, $1.0 \%$ for PM16 micelles and $0.7 \%$ for PM32 micelles after 6 days (Table 3). Furthermore, we investigated the hydrolytic stability of the ester functions in PM16 and in PM32 at pH 5.0 and $6.0\left(37^{\circ} \mathrm{C}\right)$, to analyze their behavior in acidic environments, which may occur in tissues or cells. Encouragingly, in all conditions both micelles were found to be hydrolytically stable, with $\leq 1.3 \%$ of 1 released in all cases after 6 days (Table 3). For all the experiments, the absence of the characteristic peaks of 4-(methylthio)phenol (reference spectrum in SI) showed that the 4-(methylthio)phenyl ester units do not directly hydrolyze. On the other hand, the release of $\mathbf{1}$ indicated background oxidation of the sulfide groups attached to the polymeric chain, enabling hydrolysis of the esters. This would demonstrate that the hydrolysis occurs exclusively after the oxidation of the thioether moiety. Nevertheless, such phenomenon can be considered negligible compared to the effect of the addition of $\mathrm{H}_{2} \mathrm{O}_{2}$ reported above, in which the hydrolysis of the pendent esters was complete within hours. Overall, we could confirm that PM16 and PM32 micelles are resistant to direct hydrolysis of 4-(methylthio)phenyl esters in environments with $\mathrm{pH}$ ranging from 5.0 to 7.4, demonstrating a unique response to oxidative stimulus.

Table 3. Oxidant-free release (\%) of 1 from PM16 and PM32 micelles after 6 days at different $\mathrm{pH}$.

\begin{tabular}{ccc} 
pH & $\begin{array}{c}\text { Release of 1 } \\
\text { from PM16 (\%) }\end{array}$ & $\begin{array}{c}\text { Release of 1 } \\
\text { from PM32 (\%) }\end{array}$ \\
\hline 7.4 & 1.0 & 0.7 \\
6.0 & 1.3 & 0.9 \\
5.0 & 1.1 & 0.8 \\
\hline
\end{tabular}

\subsection{Morphological study of oxidation of $p\left(D M A_{n}-b-M T P A_{m}\right)$ micelles}

Having established the concept, we studied the morphological response of the micelles to various concentrations of $\mathrm{H}_{2} \mathrm{O}_{2}$. PM16 micelles $(0.9 \mathrm{mM}$ thioether units at $0.9 \mathrm{mg} / \mathrm{mL})$ were exposed to concentrations of 2.0, 0.2 and $0.007 \mathrm{wt} \%$ of $\mathrm{H}_{2} \mathrm{O}_{2}$ (DLS, Figure 3A), corresponding respectively to 600,60 and $2 \mathrm{mM}$. Upon addition of $2.0 \mathrm{wt} \% \mathrm{H}_{2} \mathrm{O}_{2}$, we could not observe changes in Z-average diameter in the first hour (Figure 3A top, - red line). However, the scatter count dropped from 2.8 to $2.0 \mathrm{Mcps}$ (Figure 3A bottom, $\square$ red line), indicating that the micelles started to dissociate. In the 
next hour, the Z-average diameter of PM16 micelles shifted from approximately 32 to $48 \mathrm{~nm}$, with the scatter count further decreasing to $1.0 \mathrm{Mcps}$. After $4 \mathrm{~h}$, the PM16 micelles reached a maximum Z-average diameter of $108 \mathrm{~nm}$. The approximate 3-fold reduction in scatter count observed after $\mathrm{H}_{2} \mathrm{O}_{2}$ addition indicates degradation of the micelles after oxidation induced hydrolysis. While the concurrent increase in Z-average diameter may be counterintuitive, it can be explained by a partial clustering of the hydrolyzed polymer chains. With the aim to confirm the change in the PM16 micelles, we acquired TEM images before (Figure 3B) and $24 \mathrm{~h}$ after the addition of $2.0 \mathrm{wt} \%$ $\mathrm{H}_{2} \mathrm{O}_{2}$. We observed defined micelles before $\mathrm{H}_{2} \mathrm{O}_{2}$ addition, but could not detect any significant structure $24 \mathrm{~h}$ after oxidant addition (Figure S5C, Supporting Information). This analysis supported the rapid disruption (within 4 hours) of the polymeric micelles after addition of $2.0 \mathrm{wt} \%$ $\mathrm{H}_{2} \mathrm{O}_{2}$, as showed in both DLS and ${ }^{1} \mathrm{H}$ NMR data. We then explored lower concentrations of $\mathrm{H}_{2} \mathrm{O}_{2}$ to see if PM16 micelles could also be triggered with $0.2 \mathrm{wt} \% \mathrm{H}_{2} \mathrm{O}_{2}$. Z-average diameter and scatter count after $24 \mathrm{~h}$ (Figure $3 \mathrm{~A}, \boldsymbol{\Delta}$ blue line) were similar to those observed for $2.0 \mathrm{wt} \%$ in the first 4 hours. Interestingly, this could be interpreted as $\sim 6$ fold reduction in rate of disassembly of the micelles when the concentration of $\mathrm{H}_{2} \mathrm{O}_{2}$ is 10 times lower.

Encouraged by these promising results, we decided to investigate whether the system is able to respond to concentrations of the oxidant approaching biologically relevant conditions $(0.007 \mathrm{wt} \%$ $(2 \mathrm{mM})$ of $\mathrm{H}_{2} \mathrm{O}_{2}$ ). After an induction time of $120 \mathrm{~h}$, the Z-average diameter of PM16 micelles began to increase, ultimately reaching $108 \mathrm{~nm}$ after $336 \mathrm{~h}$ (Figure $3 \mathrm{~A}$ top, green line). Similarly, the scatter count decreased steadily from $48 \mathrm{~h}$, getting to $1.2 \mathrm{Mcps}$ at $168 \mathrm{~h}$ (Figure 3A bottom, green line). It is important to note that, in the absence of $\mathrm{H}_{2} \mathrm{O}_{2}$ the PM16 micelles remained stable at $32-34 \mathrm{~nm}$ and $3.2-3.7 \mathrm{Mcps}$ for $336 \mathrm{~h}$. These results demonstrate a sensitivity down to 0.007 $\mathrm{wt} \% \mathrm{H}_{2} \mathrm{O}_{2}$ and a considerable stability in the absence of an oxidative trigger.

Next, we repeated the same DLS study with PM32 micelles ( $1.8 \mathrm{mM}$ thioether units at $0.9 \mathrm{mg} / \mathrm{mL})$. These micelles showed similar behavior to PM16 micelles, with a sigmoidal increase in Z-average diameter and a sigmoidal decrease in scatter count after $\mathrm{H}_{2} \mathrm{O}_{2}$ addition. Specifically, the Z-average diameter of PM32 micelles increased from 42 to $90 \mathrm{~nm}$ (Figure 3C top), while the scatter count dropped from 8.0 to $1.0 \mathrm{Mcps}$ (Figure 3C bottom). The lower plateau value of the scatter count was reached 7 and $48 \mathrm{~h}$ after the addition of $2.0 \mathrm{wt} \% \mathrm{H}_{2} \mathrm{O}_{2}$ and $0.2 \mathrm{wt} \% \mathrm{H}_{2} \mathrm{O}_{2}$, respectively. Showing that, similarly to PM16, PM32 micelles disrupted $\sim 6$ times slower when 10 times lower oxidant concentration was used. For $0.007 \mathrm{wt} \%(2.0 \mathrm{mM}) \mathrm{H}_{2} \mathrm{O}_{2}$, the scatter count dropped to 3.2 
Mcps after $336 \mathrm{~h}$ (Figure 3C bottom, green line). Considering that here the ratio of thioether units $/ \mathrm{H}_{2} \mathrm{O}_{2}$ was nearly 1 , the low rate of micellar disruption is not surprising. Additionally, like the PM16 micelles, the scatter count remained relatively stable $(7.3-8.5 \mathrm{Mcps})$ over $336 \mathrm{~h}$ without $\mathrm{H}_{2} \mathrm{O}_{2}$.

Curiously, the aggregates formed after the disruption of PM32 were apparently smaller than those obtained from PM16. So, to further investigate, we acquired TEM images of PM32 micelles before (Figure 3D) and $24 \mathrm{~h}$ after the addition of $2.0 \mathrm{wt} \% \mathrm{H}_{2} \mathrm{O}_{2}$ (Figure S5D, Supporting Information). With these images we could see the initial spherical micelles, but could not distinguish any particular structure after the treatment with $\mathrm{H}_{2} \mathrm{O}_{2}$. We therefore imaged PM32 micelles before (Figure S7C, Supporting Information) and $24 \mathrm{~h}$ after (Figure S7D, Supporting Information) the addition of $0.2 \mathrm{wt} \% \mathrm{H}_{2} \mathrm{O}_{2}$ by Cryo-EM. The particle analysis showed a relatively small increase in average diameter from $19.2 \pm 2.3$ (Figure S7A, Supporting Information) to $28.9 \pm 15.4 \mathrm{~nm}$ (Figure S7B, Supporting Information). In this case, Cryo-EM images supported the increase in size for PM32 micelles upon addition of $\mathrm{H}_{2} \mathrm{O}_{2}$. On the other hand, Cryo-EM images of PM16 micelles (Figure S6, Supporting Information) before and $24 \mathrm{~h}$ after the addition of $0.2 \mathrm{wt} \% \mathrm{H}_{2} \mathrm{O}_{2}$ showed the starting spherical and homogeneous micelles in non-oxidative conditions, but, similar to the TEM images, did not show any significant structure after the $\mathrm{H}_{2} \mathrm{O}_{2}$ addition. The low scatter count associated with the proposed larger aggregates indicates a very low abundance, explaining the result of Cryo-EM imaging. Despite of the uncertain characterization of the final structures, the Z-average diameter change and the decrease in scatter count of the micelles at different concentrations of $\mathrm{H}_{2} \mathrm{O}_{2}$ measured by DLS demonstrated the oxidation-triggered morphological change of both PM16 and PM32 micelles.

Interestingly, the DLS data not only agreed with the ${ }^{1} \mathrm{H}$ NMR results, but also followed similar sigmoidal trends, confirming the autocatalytic degradation of our micelles. We observed that micelles prepared from PM16 underwent a faster (2 - 4 times depending on the conditions and methods of measurements) disassembly than those from PM32. The greater $\mathrm{H}_{2} \mathrm{O}_{2}$ sensitivity observed for PM16 indicates that shorter 4-(methylthio)phenyl ester functionalized blocks allow for faster micellar degradation. In perspective, this opens the possibility of tuning the hydrophobic block length of $\mathrm{p}\left(\mathrm{DMA}_{\mathrm{n}}-\mathrm{b}-\mathrm{MTPA}_{\mathrm{m}}\right)$ to precisely control drug release. 
A

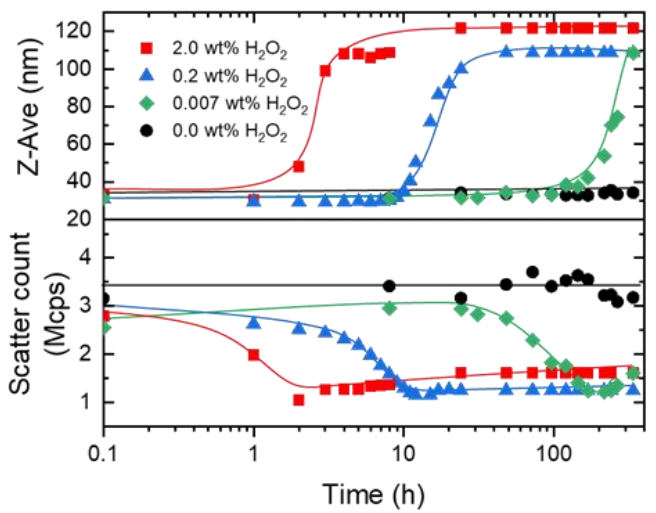

C

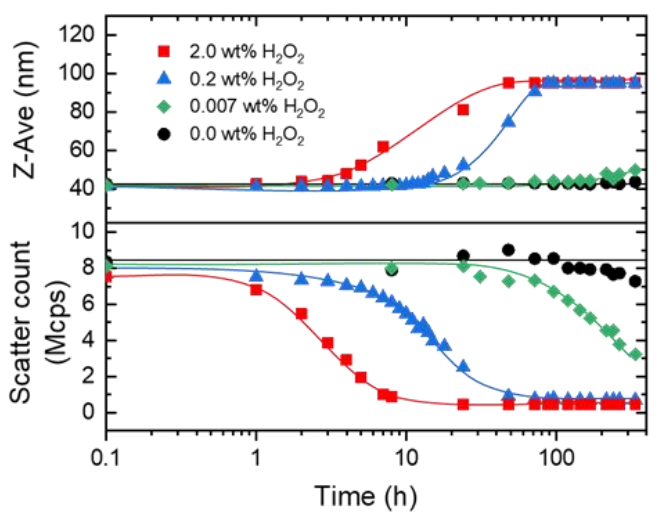

B

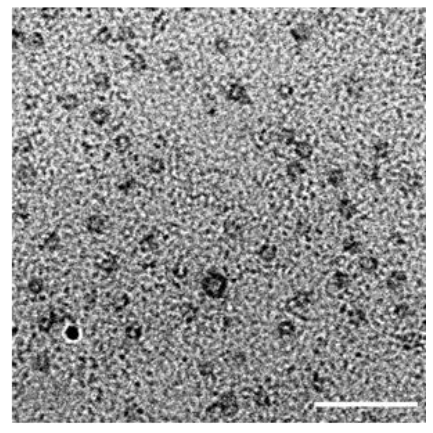

D

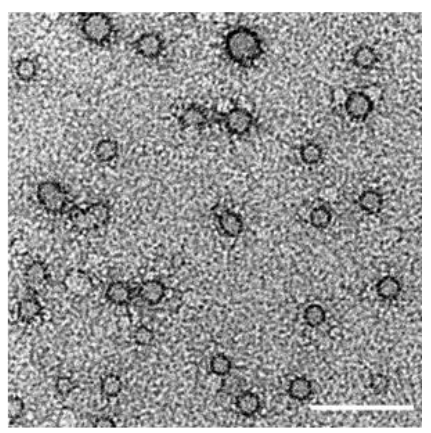

Figure 3. Morphological study of oxidation of PM16 and PM32 micelles. The curves are drawn as a guide for the eye. A) Z-Average diameter (top) and scatter count (bottom) of PM16 micelles $(0.9 \mathrm{mg} / \mathrm{mL})$ measured by DLS at $37{ }^{\circ} \mathrm{C}$ for four concentrations of $\mathrm{H}_{2} \mathrm{O}_{2}: 2.0 \mathrm{wt} \%$ ( red line), 0.2 $\mathrm{wt} \%$ ( $\boldsymbol{\Delta}$ blue line), $0.007 \mathrm{wt} \%$ ( $\diamond$ green line) and $0.0 \mathrm{wt} \%$ (control $\bullet$ black line). B) TEM image $($ Scale $b a r=100 \mathrm{~nm})$ of PM16 micelles at $\mathrm{t}=0$, stained with $2.0 \mathrm{wt} \%$ uranyl acetate. $\mathbf{C}) \mathrm{Z}$-Average diameter (top) and scatter count (bottom) of PM32 micelles $(0.9 \mathrm{mg} / \mathrm{mL})$ measured by DLS at 37 ${ }^{\circ} \mathrm{C}$ for four concentrations of $\mathrm{H}_{2} \mathrm{O}_{2}: 2.0 \mathrm{wt} \%$ ( red line), $0.2 \mathrm{wt} \%$ ( $\boldsymbol{\Delta}$ blue line), $0.007 \mathrm{wt} \%$ ( green line) and $0.0 \mathrm{wt} \%$ (control $\bullet$ black line). D) TEM image (Scale bar $=100 \mathrm{~nm})$ of PM32 micelles at $\mathrm{t}=0$, stained with $2.0 \mathrm{wt} \%$ uranyl acetate. 


\subsection{Assessment of Nile Red loading and release}

To assess the suitability of $\mathrm{p}\left(\mathrm{DMA}_{\mathrm{n}}-\mathrm{b}-\mathrm{MTPA} \mathrm{A}_{\mathrm{m}}\right)$ micelles as carriers for drug release, we chose Nile Red, a non-water soluble dye which is fluorescent exclusively in a hydrophobic environment. The fluorescence of Nile Red can be constant in presence of up to 5 vol\% $(\sim 7.3 \mathrm{wt} \%) \mathrm{H}_{2} \mathrm{O}_{2}$ over $170 \mathrm{~h},{ }^{[52]}$ making it a good drug model for the time range and conditions of our experiments. First, we determined the drug loading (DL) and encapsulation efficiency (EE) of Nile Red using a known fluorescence method. ${ }^{[25]} \mathrm{We}$ obtained DL $(2.0-4.0 \mu \mathrm{g} / \mathrm{mg}$ polymer) and EE $(10-20 \%)$ (Table S3, Supporting Information), comparable to other drug release systems reported in literature. ${ }^{[25]}$ We subsequently tested the Nile Red loaded $p\left(D_{M A}-b-M T P A_{m}\right)$ micelles for release of Nile Red under oxidative conditions. PM16 micelles led to a $90 \%$ Nile Red release within 3 and $13 \mathrm{~h}$ when $2.0 \mathrm{wt} \%$ and $0.2 \mathrm{wt} \%$ of $\mathrm{H}_{2} \mathrm{O}_{2}$ was respectively added (Figure 4, top). PM32 micelles released Nile Red on longer time scales (Figure 4, bottom part), getting to $90 \%$ within $5 \mathrm{~h}\left(2.0 \mathrm{wt} \% \mathrm{H}_{2} \mathrm{O}_{2}\right.$ ) and $21 \mathrm{~h}\left(0.2 \mathrm{wt} \% \mathrm{H}_{2} \mathrm{O}_{2}\right)$. These results showed, similarly to the ${ }^{1} \mathrm{H}$ NMR data, that PM16 micelles disassembled and released the cargo almost 2 times faster than PM32 micelles in presence of the same $\mathrm{H}_{2} \mathrm{O}_{2}$ concentration. We again would like to highlight that the Nile Red release curves presented sigmoidal shapes, in line with the data acquired with the previous techniques. Specifically the release profile from PM16 micelles at $0.2 \mathrm{wt} \%$ of $\mathrm{H}_{2} \mathrm{O}_{2}$ displayed a three stage profile, typical of polymeric drug delivery systems with a heterogeneous degradation mechanism. ${ }^{[53]}$ Interestingly, this behavior does not show any burst release, increasing the relevance of the system for applications where burst release of cytotoxic drugs may cause excessive side effects. ${ }^{[54]} \mathrm{We}$ observed $10 \%$ release for PM32 micelles in a non-oxidative environment and $3 \%$ for PM16 by $30 \mathrm{~h}$. This would suggest only minor passive leaking of Nile Red from the micelles. However, such effect can be considered negligible when compared to the release rate obtained in presence of $\mathrm{H}_{2} \mathrm{O}_{2}$. Overall, the release profile shows a dependence on the type of polymer and on the concentration of $\mathrm{H}_{2} \mathrm{O}_{2}$, making this technology potentially tunable according to the required dosage and release time of the drug. 


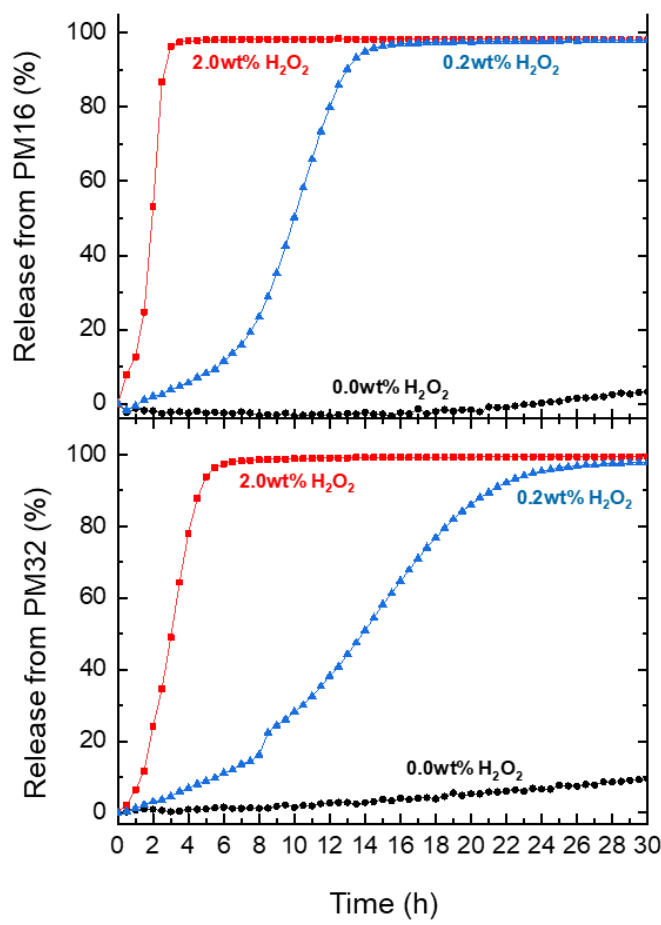

Figure 4. Nile Red release from PM16 (top) and PM32 (bottom) micellar dispersion (0.9 mg/mL) in $\mathrm{PB}(100 \mathrm{mM}, \mathrm{pH}=7.4)$ for three concentrations of $\mathrm{H}_{2} \mathrm{O}_{2}$ at $37^{\circ} \mathrm{C}: 2.0 \mathrm{wt} \%$ ( $\mathbf{r e d}$ line), $0.2 \mathrm{wt} \%$ ( $\boldsymbol{\Delta}$ blue line) and $0.0 \mathrm{wt} \%$ (control $\bullet$ black line) measured by fluorescence spectroscopy $\left(\lambda_{\text {ex }}=\right.$ $\left.540 \pm 20 \mathrm{~nm}, \lambda_{\mathrm{em}}=620 \pm 30 \mathrm{~nm}\right)$.

\subsection{Cell viability assay of $\mathbf{p}\left(\mathrm{DMA}_{\mathrm{n}}-\mathrm{b}-\mathrm{MTPA} \mathrm{A}_{\mathrm{m}}\right)$ micelles}

We tested the cytotoxicity of PM16 and PM32 micelles on HeLa cells, by administering micellar dispersions in concentrations between 0.0 and $1.0 \mathrm{mg} / \mathrm{mL}$, in line with the concentration used for the morphological study and Nile Red release. After $24 \mathrm{~h}$ of incubation, the WST-8 assay showed high cell viability for both polymers across all the applied concentrations, with no statistical difference compared to the controls (Figure S10, Supporting Information). 


\section{Conclusion}

In this work, we demonstrate selective ROS triggered breakdown of block copolymer micelles, and associated release of model cargo. The disruption mechanism is programmed into the material using a solubility switch in the hydrophobic block, based on a logic gate that increases the ester hydrolytic lability upon oxidation of a thioether phenyl moiety. In the absence of oxidants, such as $\mathrm{H}_{2} \mathrm{O}_{2}$, the micelles are stable for several days under neutral and mildly acidic buffered conditions (pH $5.0-7.4,37^{\circ} \mathrm{C}$ ). Millimolar concentrations of $\mathrm{H}_{2} \mathrm{O}_{2}$ lead to micellar disintegration and cargo release on timescales of hours to days depending on the ROS concentration. From these encouraging results, our laboratory is currently investigating methods to further increase the ROS sensitivity of these micelles to concentrations typically present in cancerous tissue, as well as studying the release of bioactive compounds and their in vivo evaluation.

\section{Acknowledgments}

The authors acknowledged financial support by the Netherlands Organisation for Scientific Research and the National Natural Science Foundation of China (NWO-NSFC joint project).

\section{Conflict of interest}

The authors declare no conflict of interest. 


\section{References}

[1] M. L. Adams, A. Lavasanifar, G.S. Kwon, J. Pharm. Sci. 2003, 92, 1343.

[2] A. Zhang, K. Jung, A. Li, J. Liu, C. Boyer, Prog. Polym. Sci. 2019, 99, 101164.

[3] K. Zhou, H. Liu, S. Zhang, X. Huang, Y. Wang, G. Huang, B. D. Sumer, J. Gao, J. Am. Chem. Soc. 2012, 134, 7803.

[4] E. M. Frazar, R. A. Shah, T. D. Dziubla, J. Z. Hilt, J. Appl. Polym. Sci. 2020, 137, 48770.

[5] T. Miyata, N. Asami, T. Uragami, Nature 1999, 399, 766.

[6] C. C. Winterbourn, Nat. Chem. Biol. 2008, 4, 278.

[7] S. C. Gupta, D. Hevia, S. Patchva, B. Park, W. Koh, B. B. Aggarwal, Antioxid. Redox Signaling 2012, 16, 1295.

[8] L. M. Coussens, Z. Werb, Nature 2002, 420, 860.

[9] T. Wu, X. Chen, Y. Wang, H. Xiao, Y. Peng, L. Lin, W. Xia, M. Long, J. Tao, X. Shuai, Nanomedicine 2018, 14, 2215.

[10] K. J. Barnham, C. L. Masters, A. I. Bush, Nat. Rev. Drug Discovery 2004, 3, 205.

[11] L. M. Sayre, G. Perry, M. A. Smith, Chem. Res. Toxicol. 2008, 21, 172.

[12] S. Loft, H.E. Poulsen, J. Mol. Med. 1996, 74, 297.

[13] P. D. Ray, B.W. Huang, Y. Tsuji, Cell. Signalling 2012, 24, 981.

[14] S. B. Nimse, D. Pal, RSC Adv. 2015, 5, 27986.

[15] C. T. Jordan, J. Z. Hilt, T. D. Dziubla, J. Appl. Polym. Sci. 2019, 137, 48647.

[16] C. Tapeinos, A. Pandit, Adv. Mater. 2016, 28, 5553.

[17] H. Hagen, P. Marzenell, E. Jentzsch, F. Wenz, M. R. Veldwijk, A. Mokhir, J. Med. Chem. 2012, 55, 924.

[18] C.-C. Song, F.-S. Du, Z.-C. Li, J. Mater. Chem. B 2014, 2, 3413.

[19] D. Trachootham, J. Alexandre, P. Huang, Nat. Rev. Drug Discovery 2009, 8, 579.

[20] E. Lallana, N. Tirelli, Macromol. Chem. Phys. 2013, 214, 143.

[21] A. Napoli, M. Valentini, N. Tirelli, M. Muller, J. A. Hubbell, Nat. Mater. 2004, 3, 183.

[22] D. Jeanmaire, J. Laliturai, A. Almalik, P. Carampin, R. d'Arcy, E. Lallana, R. Evans, R. E. P. Winpenny, N. Tirelli, Polym. Chem. 2014, 5, 1393.

[23] V. V. Khutoryanskiy, N. Tirelli, Pure Appl. Chem. 2008, 80, 1703.

[24] F. El Mohtadi, R. d'Arcy, J. Burke, J. M. Rios De La Rosa, A. Gennari, R. Marotta, N. Francini, R. Donno, N. Tirelli, Biomacromolecules 2020, 21, 305. 
[25] P. Hu, N. Tirelli, Bioconjug. Chem. 2012, 23, 438.

[26] K. E. Broaders, S. Grandhe, J. M. Frechet, J. Am. Chem. Soc. 2011, 133, 756.

[27] K. Sato, M. Takahashi, M. Ito, E. Abe, J.-i. Anzai, Langmuir 2014, 30, 9247.

[28] C. de Gracia Lux, S. Joshi-Barr, T. Nguyen, E. Mahmoud, E. Schopf, N. Fomina, A. Almutairi, J. Am. Chem. Soc. 2012, 134, 15758.

[29] T. Zhang, X. Chen, C. Xiao, X. Zhuang, X. Chen, Polym. Chem. 2017, 8, 6209.

[30] C. Dong, Q. Zhou, J. Xiang, F. Liu, Z. Zhou, Y. Shen, J. Controlled Release 2020, 321, 529.

[31] F. Y. Qiu, M. Zhang, R. Ji, F. S. Du, Z. C. Li, Macromol. Rapid. Commun. 2015, 36, 2012.

[32] X. Liu, J. Xiang, D. Zhu, L. Jiang, Z. Zhou, J. Tang, X. Liu, Y. Huang, Y. Shen, Adv. Mater. 2016, 28, 1743.

[33] S. Lv, Y. Wu, K. Cai, H. He, Y. Li, M. Lan, X. Chen, J. Cheng, L. Yin, J. Am. Chem. Soc. 2018, 140, 1235.

[34] E. Jäger, J. Humajová, Y. Dölen, J. Kučka, A. Jäger, R. Konefał, J. Pankrác, E. Pavlova, T. Heizer, L. Šefc, M. Hrubý, C. G. Figdor, M. Verdoes, Adv. Healthcare Mater. 2021, 2100304.

[35] A. Gennari, C. Gujral, E. Hohn, E. Lallana, F. Cellesi, N. Tirelli, Bioconjugate Chem. 2017, $28,1391$.

[36] F. El-Mohtadi, R. d'Arcy, N. Tirelli, Macromol. Rapid Commun. 2019, 40, 1800699.

[37] W. L. Paul Charlesworth, William S. Jenks, J. Phys. Chem. 1996, 100, 15152.

[38] F. Cheng, T. Su, K. Luo, Y. Pu, B. He, Journal of Materials Chemistry B 2019, 7, 1005.

[39] M. Geven, R. d'Arcy, Z. Y. Turhan, F. El-Mohtadi, A. Alshamsan, N. Tirelli, European Polymer Journal 2021, 149.

[40] W.-X. Wu, X.-L. Yang, B.-Y. Liu, Q.-F. Deng, M.-M. Xun, N. Wang, X.-Q. Yu, RSC Advances 2016, 6, 11870.

[41] C. Brooker, R. d'Arcy, E. Mele, H. Willcock, Soft Matter 2021, 17, 3775.

[42] C. D. Vo, G. Kilcher, N. Tirelli, Macromol. Rapid Commun. 2009, 30, 299.

[43] W. Mabey, T. Mill, J. Phys. Chem. Ref. Data 1978, 7, 383.

[44] J. M. Caster, S. K. Yu, A. N. Patel, N. J. Newman, Z. J. Lee, S. B. Warner, K. T. Wagner, K. C. Roche, X. Tian, Y. Min, A. Z. Wang, Nanomedicine 2017, 13, 1673.

[45] D. J. Keddie, Chem. Soc. Rev. 2014, 43, 496. 
[46] Z. Ahmad, A. Shah, M. Siddiq, H.-B. Kraatz, RSC Adv. 2014, 4, 17028.

[47] M. C. Jones, J.C. Leroux, Eur. J. Pharm. Biopharm. 1999, 48101.

[48] A. G. Denkova, H. Liu, Y. Men, R. Eelkema, Adv. Therap. 2020, 3, 1900177.

[49] H. Cabral, Y. Matsumoto, K. Mizuno, Q. Chen, M. Murakami, M. Kimura, Y. Terada, M. R. Kano, K. Miyazono, M. Uesaka, N. Nishiyama, K. Kataoka, Nat. Nanotechnol. 2011, 6,815 .

[50] M. Chen, Y. Jin, J. Li, Y. Zhang, X. Li, Ind. Eng. Chem. Res. 2017, 56, 7675.

[51] S. Fredenberg, M. Wahlgren, M. Reslow, A. Axelsson, Int. J. Pharm. 2011, 415, 34.

[52] M. K. Gupta, T. A. Meyer, C. E. Nelson, C. L. Duvall, J. Controlled Release 2012, 162, 591.

[53] T. G. Park, Biomaterials 1995, 16, 1123.

[54] N. Kamaly, B. Yameen, J. Wu, O. C. Farokhzad, Chem. Rev. 2016, 116, 2602. 